\title{
Análise da Distribuição dos Financiamentos Rurais entre os Estabelecimentos Agropecuários Brasileiros
}

\author{
Paulo Marcelo de Souza ${ }^{1}$, Marlon Gomes $\mathrm{Ney}^{2}$ e \\ Niraldo José Ponciano ${ }^{3}$
}

Resumo: Com a pesquisa, buscou-se analisar a distribuição do uso de financiamentos entre os estabelecimentos, considerando tais critérios: número de estabelecimentos e participação no valor da produção. Para analisar essa distribuição foram calculados o percentual dos financiamentos utilizados pelos $50 \%$ menores e pelos cinco e $10 \%$ maiores estabelecimentos, o valor médio financiado e o índice de concentração. Os resultados permitiram concluir que a distribuição dos financiamentos entre os estabelecimentos agropecuários é concentrada, mas tende a refletir as diferenças desses estabelecimentos quanto à sua contribuição para o valor da produção. Tal constatação decorre dos efeitos dos financiamentos do Pronaf, que favorecem os estabelecimentos dos estratos inferiores de área. $\mathrm{Na}$ ausência desse programa, a distribuição dos programas governamentais de crédito seria bem mais concentrada. Porém, as mudanças nas regras de operacionalização desse programa, que favorecem agricultores mais capitalizados e as regióes onde predominam, vêm, provavelmente, reduzindo esse efeito.

Palavras-chaves: Estrutura agrária; Crédito; Desigualdade distributiva; Pronaf.

Abstract: The objective of the research was to analyze the distribution of the credit use between the rural establishments, considering, as criteria, the number of establishments and participating in production value. To analyze this distribution, the percentage of credit used by the 50\% lower and by the 5 and 10\% larger establishments, the average value financed and the concentration index were calculated. The results showed that the distribution of funding between the agricultural establishments are concentrated, but tends to reflect the differences of these establishments with respect their contribution to

1. Universidade Estadual do Norte Fluminense Darcy Ribeiro. Campos dos Goytacazes, Rio de Janeiro, Brasil. E-mail: pmsouza@uenf.br

2. Universidade Estadual do Norte Fluminense Darcy Ribeiro. Campos dos Goytacazes, Rio de Janeiro, Brasil. E-mail: marlon@uenf.br

3. Universidade Estadual do Norte Fluminense Darcy Ribeiro. Campos dos Goytacazes, Rio de Janeiro, Brasil. E-mail: ponciano@uenf.br 
the production value. This result is related to the effects of Pronaf, a program that benefits the establishments of the lower strata of area. In the absence of this program, the distribution of the government programs of credit would be much more concentrated. However, changes in the operational rules of this program, which favor more capitalized farmers and regions where they predominate, are probably reducing this effect.

Key-words: Agrarian structure; Credit; Distributive inequality; Pronaf.

http://dx.doi.org/10.1590/1234-56781806-9479005302004

\section{Introdução}

O crédito é considerado um dos principais instrumentos de incentivo à agricultura, setor onde, dentre outras especificidades, há significativa defasagem temporal entre o investimento na produção e as receitas decorrentes desse investimento. Trata-se de um elemento central na política agrícola utilizado para promover ganhos de produtividade, contribuindo para o aumento da produção por meio do rendimento da terra e dos fatores de produção (BELIK, 2014).

No Brasil, o crédito rural adquiriu importância a partir da década de 1960 com a criação do Sistema Nacional de Crédito Rural (SNCR), responsável, em grande parte, pela modernização agrícola que ocorreria a partir de então. Não obstante o reconhecimento da importância dessa política, ela tem sido criticada, dentre outros aspectos, pela questão distributiva.

Abundante no período da modernização da agricultura, essa política, segundo Silva et al. (1983), beneficiou principalmente a região Centro-Sul do País, em detrimento do NorteNordeste, favorecendo essencialmente os produtos modernos e utilizadores de tecnologias mais avançadas, além de privilegiar os grandes produtores. Conforme Sayad (1984), o crédito rural subsidiado atuou como instrumento concentrador de riqueza, pois seus recursos foram concedidos aos produtores que pudessem oferecer maiores garantias reais, sendo a terra a principal delas, num processo perverso de redistribuição da riqueza em favor dos mais ricos. Aos agricultores que dele se beneficiaram, os estímulos do crédito rural facultaram uma dianteira no processo de modernização e um crescente distanciamento daqueles que, alijados dessa e de outras políticas, mantiveram-se em sistemas produtivos tradicionais (SZMRECSÁNYI e RAMOS, 2002).

Santos e Braga (2013) ressaltam que, nas décadas de 1970 e 1980, a distribuição do crédito se deu em função do tamanho dos estabelecimentos dos tomadores, o que favoreceu grandes proprietários. Não podendo oferecer garantias, os menores estabelecimentos se viram diante de barreiras que terminaram por lhes impor restrições de acesso ao crédito. Essas restrições se agravariam mais tarde, com a crise econômica da década de 1980.

Após um período de redução na utilização do crédito rural, o financiamento à agricultura voltou a crescer no final da década de 90. Porém, conforme Belik (2013), o volume de crédito rural disponibilizado aos produtores ainda é reduzido em relação às suas necessidades. De fato, uma das características do crédito rural no Brasil é que o acesso aos recursos tem sido restrito (SPOLADOR e LIMA, 2010). O setor agropecuário apresenta uma série de características como alta sazonalidade, informações assimétricas, riscos climáticos, entre outras, que elevam os riscos envolvidos e 
dificultam a concessão de crédito. Com isso, tem-se um mercado de crédito racionado no qual uma pequena parcela dos produtores consegue acessar os financiamentos (EUSÉBIO e PENHA, 2014).

Segundo Assunção e Chien (2007), tal racionamento está associado às imperfeições no mercado de crédito, em geral determinadas por problemas de informação. Trata-se de uma situação em que os provedores de crédito não conseguem observar aspectos como: o tipo de seus clientes, o que eles fazem com os recursos emprestados ou se estão dispostos a pagar o empréstimo. No caso da população rural brasileira, ressaltam os autores, essas questões são exacerbadas pela distância dessa população ao mercado financeiro formal. Conforme Spolador (2001), no caso do crédito à informação, torna-se uma falha no mercado que restringe o volume de recursos privados $\mathrm{e}$ faz com que o equilíbrio de mercado se dê com excesso de demanda por empréstimos, pois, dado o problema da seleção adversa, a oferta de crédito é feita a uma taxa inferior à de equilíbrio entre oferta e demanda.

Conforme Santos e Braga (2013), como a taxa de juros no mercado de crédito rural tem sido fixada abaixo do ponto de equilíbrio, o problema posto ao intermediário financeiro é a minimização de seus custos. Diante disso, os problemas de informação tornam-se relevantes. Nesse contexto, a dispersão geográfica (dificuldade com supervisão, recuperação de créditos, obtenção de informações etc.), os problemas com garantias, o pequeno tamanho dos empréstimos e os riscos inerentes à atividade rural são fatores que elevam o custo das operações de financiamento da agricultura. Esses fatores elevam a exigência dos agentes financeiros na concessão do crédito e influenciam negativamente sua oferta.

Os altos custos de transação envolvidos nas operações de crédito também são apontados como responsáveis pela restrição de crédito na agricultura (SPOLADOR, 2001). No setor agrícola, que apresenta uma série de características que tornam mais arriscada a concessão dos empréstimos, do ponto de vista dos emprestado- res, as dificuldades no acesso ao crédito são maiores (EUSÉBIO e PENHA, 2014). Isso porque, ao tentar minimizar esses riscos, o sistema financeiro utiliza mecanismos de seleção e monitoramento dos tomadores, mediante contratos complexos e exigências de garantias que elevam os custos dos empréstimos, sobretudo quando em menores volumes, para pequenos produtores rurais.

Por razões diversas, o fato é que o acesso ao crédito permanece limitado. Assunção e Chein (2007), analisando especificamente famílias pertencentes às áreas rurais, encontraram evidências de que há restrição de crédito no meio rural no Brasil e em suas regiões. Santos e Braga (2013) concluíram que, no ano de 2006, 66,52\% dos estabelecimentos agropecuários que solicitaram crédito não o obtiveram, principalmente por motivos ligados às imperfeições de mercado.

Porém, há evidências de que as restrições para o acesso ao crédito não afetam igualmente os diversos tipos de produtores. Segundo Belik (2013), a distribuição do crédito rural permanece desigual e seletiva, impondo dificuldades de acesso a pequenos produtores, agricultores sem terra e outros grupos pouco articulados. Eusébio e Penha (2014) encontram evidências de menor participação das pequenas propriedades nos financiamentos, associada às restrições impostas pelas instituições financeiras. Trata-se de um mecanismo de seleção dos aptos a receber crédito pelo sistema financeiro, que favorece a categoria de proprietários e tomadores com maiores terras. Também Souza et al. (2010) afirmam que mais de $80 \%$ dos estabelecimentos familiares do país não obtiveram qualquer financiamento em 2006. Nos estados do Acre, Amapá, Amazonas, Pará, Roraima, Maranhão e Rio de Janeiro, 90\% ou mais dos agricultores não obtiveram financiamento.

As dificuldades de acesso ao crédito por pequenos produtores impostas pela seletividade e desigualdade na distribuição do crédito rural explicam, segundo Belik (2013), o crescimento de instrumentos exclusivos de financiamento a grupos mais fragilizados de agricultores. Dentre esses instrumentos, destaca-se o Programa Nacional de Fortalecimento da Agricultura Familiar (Pronaf), 
criado em 1996, visando contornar as dificuldades de acesso desse segmento ao crédito. Esse programa surge num momento em que, conforme Guanzirolli (2007), a escassez de crédito e seu elevado custo eram apontados como um dos principais problemas enfrentados pelos agricultores, especialmente os familiares. Conforme Eusébio e Penha (2014), enquanto não havia recursos direcionados para o financiamento da agricultura familiar, o pequeno produtor disputava os recursos destinados ao crédito rural com os grandes produtores, cujas garantias lhe asseguravam a obtenção dos financiamentos.

Apesar da importância desse programa, questões sobre sua operacionalização vêm sendo abordadas em vários estudos envolvendo aspectos como sua baixa abrangência, a concentração regional dos recursos, sua concentração entre os agricultores mais capitalizados, entre outras. Essas análises fornecem indícios de que a lógica desse programa não rompeu com os mecanismos de restrição e seletividade que, até então, impediram elevada parcela dos agricultores de acessar o crédito rural.

Diante dessas questões, o tema da desigualdade no uso dos financiamentos entre estabelecimentos agropecuários permanece atual. Com o objetivo de fornecer contribuições adicionais ao debate, na presente pesquisa faz-se uma análise da relação entre a distribuição dos financiamentos e a distribuição dos estabelecimentos agropecuários e do valor da produção desses estabelecimentos, considerando-se os diferentes estratos de área. Nessa análise, especial interesse recai sobre as diferenças entre os financiamentos provenientes dos programas de crédito governamentais, dos recursos não provenientes desses programas e daqueles oriundos do Pronaf.

\section{Metodologia}

\subsection{Exposição do modelo}

Para analisar a relação entre a distribuição dos financiamentos e a distribuição dos estabelecimentos agropecuários e do valor da pro- dução, foram calculados o percentual do valor dos financiamentos tomado pelos 50\% menores e pelos cinco e $10 \%$ maiores estabelecimentos, assim como o percentual dos financiamentos correspondente aos estabelecimentos responsáveis pelos primeiros $50 \%$ do valor produzido e pelos últimos $5 \%$ e $10 \%$ desse valor. Foram ainda calculados o valor médio financiado por estabelecimento e por unidade produzida e o índice de concentração. Os primeiros indicadores são comumente empregados em estudos sobre distribuição de renda e seus procedimentos de cálculo, assim como a interpretação de seus resultados, são de fácil compreensão. Quanto ao índice de concentração, uma medida similar o índice de Gini, segue uma breve descrição sobre seu cálculo e significado.

O Índice de Concentração é derivado da literatura ligada à de distribuição de renda (VIANA, SALVATO e ARAUJO, 2011). É obtido a partir do conceito, similar à curva de Lorenz, de curva de concentração. Conforme Medeiros (2006), a noção de concentração usada nas curvas de concentração diz respeito à distribuição de uma variável em uma população classificada segundo outra variável. Já a curva de Lorenz é um caso particular das curvas de concentração, em que as variáveis da distribuição e ordenação são as mesmas.

Conforme KAKWANI (1977), seja $g(x)$ uma função contínua de $x$, sua derivada existe, e $g(x) \geq 0$. Se a média $E[g(x)]$ existe, então pode-se definir

$$
F_{1}[g(x)]=\frac{1}{E[g(x)]} \int_{0}^{x} g(x) f(x) d x
$$

Em que $f(x)$ é a função densidade de probabilidade de $x$, tal que $F_{1}[g(x)]$ é monotônica crescente e $F_{1}[g(0)]=0$ e $F_{1}[g(\infty)]=1$. A relação entre $F_{1}[g(x)]$ e $F(x)$ é chamada curva de concentração da função $g(x)$. A curva de Lorenz de $x$ é um caso especial da curva de concentração da função $g(x)$ quando $g(x)=x$.

Diferentemente da curva de Lorenz, a curva de concentração não é estritamente convexa. Pode se situar acima da diagonal e, inclu- 
sive, cruzá-la em um ou mais pontos (VIANA, SALVATO e ARAUJO, 2011). A posição e a inclinação de uma curva de concentração em relação à linha de igualdade indicam a progressividade da distribuição (MEDEIROS, 2006). As funções côncavas indicam que a distribuição da variável de interesse (por exemplo, renda, valor da produção etc.) favorece os indivíduos dos estratos mais baixos da distribuição da variável de ordenação (por exemplo, área, anos de estudo, etc.), enquanto a função convexa indica iniquidade a favor dos indivíduos dos extratos mais elevados.

O índice de concentração é obtido por meio da relação entre área sob a curva de concentração e a diagonal, que, tal como no caso da curva de Lorenz, representa perfeita igualdade entre os grupos (NORONHA e ANDRADE, 2002). Essa medida corresponde a duas vezes a área entre a curva de concentração e a linha de igualdade ou, alternativamente, a um menos o dobro da área sob a curva de concentração. Conforme definição de Kakwani (1977), o Índice de concentração para $g(x)$ é definido como um menos duas vezes a área sobre a curva de concentração:

$$
C=1-2 \int_{0}^{\infty} F_{1}[g(x)] f(x) d x
$$

Na presente situação, a curva de concentração foi obtida relacionando-se a distribuição cumulativa do valor dos financiamentos com as distribuições cumulativas do número de estabelecimentos e do valor da produção. Como não se dispõe de uma função contínua para a curva de concentração, uma medida aproximada do índice de concentração foi obtida pela expressão:

$$
G=1-\sum_{i=1}^{n}\left(Y_{i}+Y_{i-1}\right)\left(X_{1}-X_{i-1}\right)
$$

em que $X_{\mathrm{i}}$ é a percentagem acumulada dos estabelecimentos ou do valor da produção até o estrato de área ou de produção $i$; $X_{\mathrm{i}-1}$ é a percentagem acumulada dos estabelecimentos ou do valor da produção até o estrato anterior ao estrato $i ; Y_{\mathrm{i}}$ é a percentagem acumulada do valor dos finan- ciamentos até o estrato de área $i ; Y_{\mathrm{i}-1}$ é a mesma percentagem acumulada até o estrato anterior ao estrato $i$; e $n$ é o número de estratos. O índice de concentração, cujos valores situam-se no intervalo de - 1 a 1 , assume valores positivos para curvas de concentração convexas e negativos para as côncavas. Quanto mais igualitária a distribuição, mais próximo de zero ele se situa (SIMÕES, PAQUETE e ARAÚJO, 2008).

\subsection{Variáveis e fontes dos dados}

A análise baseou-se em informações sobre a distribuição, entre estratos de área, do número de estabelecimentos agropecuários, dos financiamentos obtidos por esses estabelecimentos e do valor da produção que geraram. Essas informações foram obtidas da segunda apuração do Censo Agropecuário de 2006, disponíveis no Sistema de Recuperação Automática (Sidra), da Fundação Instituto Brasileiro de Geografia e Estatística (FIBGE).

Inicialmente, foi elaborada a distribuição, entre estratos de área, do número de estabelecimentos agropecuários e do respectivo valor da produção desses estabelecimentos, constituído por: produção animal (grande porte, médio porte, aves e pequenos animais), produção vegetal (lavouras permanentes, lavouras temporárias, horticultura, floricultura, silvicultura e extração vegetal) e agroindústria. Em seguida foi elaborada a distribuição do valor dos financiamentos obtidos pelos estabelecimentos agropecuários, segundo estratos de área.

$\mathrm{O}$ valor dos financiamentos (que podem ter sido obtidos junto a bancos, cooperativas de crédito, outras instituições financeiras, comerciantes de matéria prima, fornecedores de insumos e/ ou equipamentos, empresa integradora, etc.) foi segmentado, conforme denominação da fonte dos dados, quanto à proveniência dos recursos: oriundos de programas governamentais de crédito sejam eles federais, estaduais ou municipais, e não provenientes de programas governamentais de crédito. No caso dos recursos provenientes de programas governamentais, optou-se ainda 
por considerar a distinção (dada pela fonte), entre recursos provenientes do Pronaf e recursos provenientes de outros programas governamentais de crédito".

Conjugando-se as distribuições dos estabelecimentos e do valor da produção pelos diversos estratos de área, e a distribuição dos financiamentos obtidos, considerando-se os mesmos estratos de área, foram obtidas as curvas de concentração. A partir dessas curvas, foram calculados os índices de concentração.

Além das informações do Censo Agropecuário de 2006, foram também foram empregados dados do Anuário Estatístico do Crédito Rural, do Banco Central do Brasil. Esses dados foram utilizados apenas para caracterizar o comportamento mais recente da distribuição regional dos financiamentos do Pronaf, dada a inexistência de um novo censo.

\section{Resultados e discussão}

Os valores da Tabela 1 revelam que a distribuição dos financiamentos utilizados entre os estabelecimentos é concentrada, com índice de 0,76 no País. Enquanto os 50\% menores estabelecimentos empregam cerca de apenas $6,5 \%$ do total de financiamentos, os $5 \%$ maiores utilizam quase $63 \%$, e os $10 \%$ maiores $70 \%$ desse total. O valor médio financiado por estabelecimento é de $\mathrm{R} \$ 4.335,44$.

A distribuição dos financiamentos mostra-se mais concentrada na região Centro-Oeste, com índice de concentração 0,828 . Nessa região, cerca de apenas 3,8\% dos financiamentos destinaram-se aos 50\% menores estabelecimentos, e $61 \%$ desses recursos foram utilizados pelos os $5 \%$ maiores. Essa é também a região com o maior valor médio

4. Uma parcela dos financiamentos provenientes de programas governamentais de crédito é simultaneamente atribuída, no censo, ao Pronaf e a outro programa (federal, estadual ou municipal). Como essa parcela é pequena (cerca de $2 \%$ dos recursos provenientes de programas governamentais), e não sendo possível distinguir nela o programa de onde provieram os recursos, optou-se por desconsiderá-la na análise. financiado por estabelecimento: R\$ 17.860,44. Em seguida vem a região Sudeste, com índice de concentração próximo de 0,80 , onde cerca de $66 \%$ do valor dos financiamentos são tomados pelos $5 \%$ maiores estabelecimentos, ficando os $50 \%$ menores com apenas 6,1\% desse valor. Com índice de concentração um pouco mais baixo, de 0,73, encontra-se a região Nordeste. É a região com menor valor médio de financiamento tomado por estabelecimento. Nela, $63 \%$ do valor dos financiamentos destinam-se aos 5\% maiores estabelecimentos, e apenas $10,1 \%$ aos $50 \%$ menores.

Já nas regiões Norte e Sul os indicadores permitem distinguir uma distribuição menos concentrada do uso de financiamentos. Nessas regiões, com índices de concentração em torno de 0,60 , a participação dos $50 \%$ menores estabelecimentos é de cerca de $20 \%$, com os $5 \%$ maiores tomando-se pouco mais de $40 \%$ desse total. Embora com perfis semelhantes quanto à distribuição do uso de financiamentos, a região Sul se distingue por apresentar maior utilização desses recursos, o que se reflete, num valor médio por estabelecimento, quatro vezes maior do que o da região Norte.

Dentre os estados, Mato Grosso, Mato Grosso do Sul, São Paulo, Maranhão e Bahia se destacam como aqueles onde a distribuição dos financiamentos é mais concentrada, com índices na faixa de $0,80-0,86$. Nos três primeiros encontram-se os maiores valores médios de financiamento por estabelecimento do país, no que diferem de Maranhão e Bahia, onde esse indicador é baixo. Em geral, é pequena a participação dos 50\% menores estabelecimentos nos financiamentos, e elevada, de mais de $70 \%$, a participação dos 5\% maiores. Em Mato Grosso do Sul, embora menos elevada a parcela referente aos 5\% maiores estabelecimentos, os $10 \%$ maiores utilizam cerca de $80 \%$ dos financiamentos.

Essa distribuição é também concentrada em Alagoas, Distrito Federal, Espírito Santo, Goiás, Minas Gerais, com índices de concentração na faixa de 0,70-080. Nesses estados, a participação dos $50 \%$ menores estabelecimentos nos financiamentos é sempre inferior a $10 \%$, enquanto os $5 \%$ 
maiores tomam cerca de 50 a $70 \%$ do total dos financiamentos.

Em situação intermediária encontram-se os estados Paraná, Pernambuco, Roraima, Amazonas, Piauí e Rio Grande do Norte, com índices de concentração na faixa de 0,60-0,70. Neles, a participação dos $50 \%$ menores estabelecimentos situa-se entre $10-15 \%$, enquanto a dos $5 \%$ maiores corresponde a cerca de $50-60 \%$ dos financiamentos, com exceção de Amazonas, onde esse percentual é mais baixo, porém atinge quase $60 \%$ quando se consideram os $10 \%$ maiores estabelecimentos.
A distribuição um pouco menos concentrada ocorre em Tocantins, Pará, Ceará, Rio Grande do Sul e Rio de Janeiro, onde os índices de concentração ficam próximos de 0,55-0,60. Nestes estados, há maior participação dos $50 \%$ menores estabelecimento no valor dos financiamentos, em torno dos $15 \%$, ficando os $5 \%$ maiores com percentuais próximos a $40 \%$ do total. Porém, é nos estados do Acre, Amapá, Paraíba, Rondônia, Santa Catarina e Sergipe, que se encontram os índices mais baixos, em torno de 0,40 a 0,50. Nesses estados, a participação dos $50 \%$ menores estabelecimentos

Tabela 1. Indicadores da distribuição dos financiamentos entre os estabelecimentos agropecuários, 2006

\begin{tabular}{|c|c|c|c|c|c|}
\hline \multirow{2}{*}{ Região/UF } & \multicolumn{3}{|c|}{ Percentual } & \multirow{2}{*}{$\begin{array}{l}\text { Valor médio } \\
\text { (R\$) }\end{array}$} & \multirow{2}{*}{ Concentração } \\
\hline & $50 \%<$ & $10 \%>$ & $5 \%>$ & & \\
\hline Norte & 15,79 & 53,79 & 43,80 & $1.593,85$ & 0,597 \\
\hline Acre & 28,17 & 39,74 & 30,41 & 785,02 & 0,399 \\
\hline Amapá & 19,50 & 45,90 & 38,78 & $1.534,00$ & 0,498 \\
\hline Amazonas & 10,42 & 57,06 & 28,85 & 557,33 & 0,640 \\
\hline Pará & 15,71 & 51,13 & 42,96 & $1.382,38$ & 0,588 \\
\hline Rondônia & 19,89 & 44,69 & 33,21 & $1.636,24$ & 0,507 \\
\hline Roraima & 16,18 & 64,90 & 61,44 & $2.197,77$ & 0,650 \\
\hline Tocantins & 15,89 & 59,43 & 42,33 & $3.656,62$ & 0,603 \\
\hline Nordeste & 10,14 & 67,93 & 63,20 & $1.079,15$ & 0,726 \\
\hline Alagoas & 6,00 & 74,81 & 70,48 & $1.291,58$ & 0,785 \\
\hline Bahia & 7,31 & 77,13 & 73,38 & $1.324,59$ & 0,802 \\
\hline Ceará & 15,98 & 48,29 & 40,42 & 641,88 & 0,566 \\
\hline Maranhão & 4,25 & 78,42 & 74,33 & $1.711,26$ & 0,834 \\
\hline Paraíba & 20,09 & 34,46 & 26,43 & 561,04 & 0,441 \\
\hline Pernambuco & 11,34 & 61,77 & 56,13 & 862,68 & 0,683 \\
\hline Piauí & 14,72 & 58,60 & 55,37 & 889,64 & 0,626 \\
\hline Rio G. Norte & 15,04 & 56,27 & 51,35 & $1.503,29$ & 0,621 \\
\hline Sergipe & 25,78 & 34,49 & 25,66 & 582,03 & 0,376 \\
\hline Sudeste & 6,14 & 74,78 & 66,42 & $6.901,77$ & 0,798 \\
\hline Espírito Santo & 8,66 & 72,35 & 67,15 & $5.648,01$ & 0,764 \\
\hline Minas Gerais & 9,19 & 62,63 & 50,31 & $3.671,39$ & 0,702 \\
\hline Rio de Janeiro & 16,51 & 45,73 & 37,49 & 877,83 & 0,543 \\
\hline São Paulo & 4,44 & 80,49 & 73,46 & $16.571,61$ & 0,846 \\
\hline Sul & 14,90 & 52,42 & 41,31 & $6.420,35$ & 0,596 \\
\hline Paraná & 10,14 & 60,81 & 47,30 & $7.100,85$ & 0,687 \\
\hline Rio G. do Sul & 16,80 & 50,22 & 40,27 & $6.378,44$ & 0,564 \\
\hline Santa Catarina & 23,23 & 35,75 & 25,91 & $5.216,03$ & 0,431 \\
\hline Centro-Oeste & 3,76 & 79,85 & 61,04 & $17.860,44$ & 0,828 \\
\hline Distrito Federal & 5,66 & 72,42 & 56,91 & $12.047,31$ & 0,770 \\
\hline Goiás & 7,53 & 65,54 & 50,91 & $9.022,75$ & 0,735 \\
\hline Mato Grosso & 3,20 & 86,22 & 70,72 & $22.253,60$ & 0,864 \\
\hline Mato G. do Sul & 1,89 & 76,96 & 27,77 & $28.875,42$ & 0,798 \\
\hline Brasil & 6,49 & 70,33 & 62,76 & $4.335,44$ & 0,764 \\
\hline
\end{tabular}

Fonte: Elaboração própria, a partir de dados do Censo Agropecuário 2006. 
nos financiamentos situa-se na faixa de $20-25 \%$, aproximando-se dos 30\% no Acre. Já a participação dos 5\% maiores situa-se na faixa de $25-35 \%$, chegando a quase $40 \%$ no Amapá, ficando os $10 \%$ maiores com participações na faixa de $35-45 \%$.

Conforme os indicadores apresentados, a distribuição do valor dos financiamentos entre estabelecimentos é concentrada. Esse fato não é extraordinário, uma vez que há grande disparidade entre os estabelecimentos no que diz respeito ao tamanho da área e a sua capacidade de produção. No primeiro caso, as diferenças quanto ao tamanho estão associadas à desigualdade na distribuição da terra: um percentual reduzido de estabelecimentos detém a maior parte desse recurso, enquanto a maioria distribui-se na pequena parcela restante. Já as diferenças quanto à capacidade de produção decorrem não só do tamanho dos estabelecimentos, mas também do uso da tecnologia e da intensidade com que são cultivados. Disso resulta que a distribuição do valor da produção entre estabelecimentos não coincide com a distribuição da terra entre esses estabelecimentos. Na Figura 1a, pode-se notar que a distribuição do valor da produção é menos concentrada do que a distribuição da área, uma vez que sua curva de concentração está acima da curva da distribuição da área (que neste caso coincide com a curva de Lorenz). Tal fato reflete a contribuição proporcionalmente maior dos estabelecimentos dos estratos inferiores para a produção, comparada à área que ocupam.

Isso fica claro a partir da observação da Figura 1b, que mostra a curva de concentração da distribuição do valor da produção, e também do número de estabelecimentos, em função da distribuição acumulada da área, obtida conforme valores crescentes de estratos de área. Observa-se, neste caso, que a curva de concentração está sempre acima da linha de igualdade. Observa-se ainda que a produção incremental dos estratos correspondentes aos primeiros $20 \%$ da área total é mais que proporcional ao adicional de área que ocupam, respondendo por mais de $40 \%$ do valor da produção. Essa contribuição é aproximadamente proporcional nos próximos $10 \%$ da área, começando a declinar a partir dos estratos correspondentes aos $50 \%$ restantes da área total. Mais de $50 \%$ do valor produzido é obtido numa área correspondente a $30 \%$ do total.

Figura 1. (a) Curvas de concentração das distribuições da área e do valor da produção por estabelecimentos, 2006; (b) Curvas de concentração das distribuições dos estabelecimentos e do valor da produção pela área, 2006.

(a)

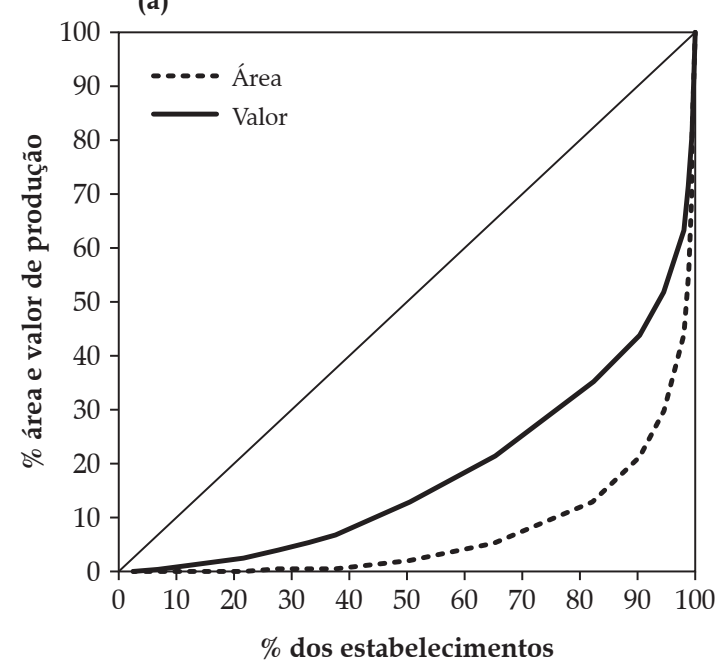

(b)

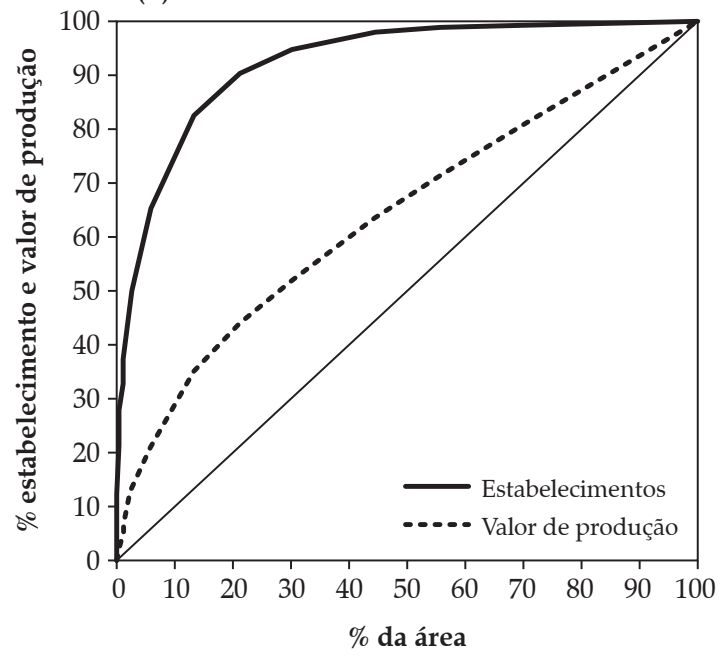

Fonte: Elaboração própria, a partir de dados do Censo Agropecuário 2006. 
Esses resultados indicam valores mais baixos de produtividade da terra nos estabelecimentos maiores, tal com observado por Helfand, Moreira e Bresnyan Junior (2014). Segundo esses autores, trata-se de uma constatação válida tanto para a agricultura não familiar quanto para a familiar (visto que esses conceitos não se baseiam exclusivamente na dimensão dos estabelecimentos), ainda que na última predominem estabelecimentos de menor porte ${ }^{5}$ Em sua análise sobre lucratividade dos estabelecimentos, Alves, Souza e Rocha (2012) encontram evidências de que os produtores malsucedidos (com renda líquida igual ou menor que zero) possuem maior área e maior patrimônio por estabelecimento, e apresentam produtividade por hectare e total dos fatores muito menores que os bem-sucedidos. Indícios, na interpretação dos autores, de má gestão dos recursos e da tecnologia disponível.

Diante de tais considerações, é interessante analisar a relação entre distribuição do valor dos financiamentos, segundo estratos de área, e a distribuição do valor da produção dos respectivos estratos. Os indicadores dessa relação, exibidos na Tabela 2, permitem concluir que há mais proporcionalidade entre a participação dos estabelecimentos no valor da produção e a fração do valor dos financiamentos que utilizam, mas isso só ocorre nos estratos superiores da distribuição. No Brasil, onde o índice de concentração aproxima-se de 0,20 , os maiores estabelecimentos, responsáveis pelos últimos 5 e $10 \%$ do valor da produção, utilizam cerca de 6,4 e $12,7 \%$ dos financiamentos. Porém os menores, responsáveis pelos primeiros $50 \%$ do valor da produção ${ }^{6}$, utilizam apenas $35,3 \%$ dos financiamentos.

5. No mesmo estudo, os autores concluem que a alta taxa de pobreza dos estabelecimentos familiares está relacionada ao tamanho reduzido de suas terras e aos baixos níveis de utilização de capital e insumos. São eficientes, no sentido de utilizar com eficiência o pouco de que dispõem, mas permanecem pobres.

6. Os índices aqui calculados fazem referência ao percentual de financiamento tomado pelos estabelecimentos conforme sua contribuição para o valor da produção. Há que se ressaltar, porém, que a distribuição acumulada da produção (e também dos financiamentos) foi construída a partir dos estratos de área. Diante disso, os termos maiores e menores estabelecimentos, aqui empregados, continuam a referir-se à dimensão área.
Essa disparidade é maior nas regiões Nordeste, com índice de concentração 0,29, e Sudeste, com índice 0,23 . Em ambas, os responsáveis pelos primeiros $50 \%$ do valor produzido utilizam cerca de apenas $32 \%$ dos financiamentos. Os estabelecimentos correspondentes aos últimos 5 e $10 \%$ do valor da produção utilizam cerca de 12,3 e 24,5\% do valor total dos financiamentos no Nordeste, e 6,8 e $13,5 \%$ no Sudeste, respectivamente.

Na região Norte, com índice de concentração próximo de 0,15 , os extratos superiores apresentam participação no crédito semelhante à fração da produção que representam, enquanto os estabelecimentos responsáveis pelos $50 \%$ produzidos utilizam $37,2 \%$ dos financiamentos.

Na região Sul, com índice 0,09 e, sobretudo na região Centro-Oeste, com índice 0,05 , encontra-se a maior correspondência entre distribuição do uso de financiamentos e participação no valor da produção. No caso da região Sul, porém, há maior disparidade entre a participação dos estabelecimentos responsáveis pela primeira metade do valor produzido e sua importância. Relativamente à produção que geram, são as regiões com maior uso de financiamentos, equivalentes a $\mathrm{R} \$ 0,14$, no Sul, e R\$ 0,19, no Centro-Oeste, por cada real produzido.

Nos estados, a distribuição dos financiamentos é mais concentrada no Espírito Santo e no Maranhão, com índices 0,48 e 0,40, respectivamente. No primeiro estado, os estabelecimentos responsáveis pelos últimos 5 e $10 \%$ da produção tomaram cerca de 34 e $55 \%$ dos financiamentos, enquanto no Maranhão essa parcela foi de aproximadamente 11,2 e 22,5\%, respectivamente. Já os estabelecimentos correspondentes aos primeiros $50 \%$ do valor da produção tomaram cerca de apenas $20 \%$ dos financiamentos nesses estados.

Em seguida vêm os estados Amazonas, Distrito Federal, Bahia e Pernambuco, com índices de concentração em torno de 0,30-0,35. O estado de São Paulo apresenta índice de concentração mais baixo, porém distintamente superior aos demais estados. Em Pernambuco, é grande a participação dos estabelecimentos dos extratos superiores, correspondentes aos $5 \%$ e $10 \%$ da 
Tabela 2. Indicadores da distribuição dos financiamentos pelo valor da produção dos estabelecimentos agropecuários, 2006

\begin{tabular}{|c|c|c|c|c|c|}
\hline \multirow{2}{*}{ Região/UF } & \multicolumn{3}{|c|}{ Percentual } & \multirow{2}{*}{$\begin{array}{c}\text { Valor médio } \\
\text { (R\$) }\end{array}$} & \multirow{2}{*}{ Concentração } \\
\hline & $50 \%<$ & $10 \%>$ & $5 \%>$ & & \\
\hline Norte & 37,19 & 9,07 & 4,54 & 0,08 & 0,145 \\
\hline Acre & 44,55 & 17,69 & 8,85 & 0,06 & 0,133 \\
\hline Amapá & 85,65 & 2,87 & 1,43 & 0,05 & $-0,228$ \\
\hline Amazonas & 19,81 & 8,95 & 1,21 & 0,05 & 0,358 \\
\hline Pará & 38,19 & 8,57 & 4,29 & 0,06 & 0,155 \\
\hline Rondônia & 41,47 & 5,43 & 2,59 & 0,10 & 0,052 \\
\hline Roraima & 38,80 & 17,64 & 8,82 & 0,18 & 0,213 \\
\hline Tocantins & 58,85 & 7,31 & 3,66 & 0,15 & $-0,095$ \\
\hline Nordeste & 32,16 & 24,51 & 12,26 & 0,09 & 0,292 \\
\hline Alagoas & 37,34 & 17,40 & 8,70 & 0,04 & 0,160 \\
\hline Bahia & 26,84 & 18,97 & 9,49 & 0,11 & 0,313 \\
\hline Ceará & 40,73 & 24,80 & 9,08 & 0,06 & 0,142 \\
\hline Maranhão & 20,36 & 22,46 & 11,23 & 0,13 & 0,401 \\
\hline Paraíba & 52,16 & 16,41 & 14,91 & 0,06 & $-0,014$ \\
\hline Pernambuco & 33,68 & 42,25 & 24,37 & 0,05 & 0,294 \\
\hline Piauí & 38,66 & 20,81 & 10,41 & 0,16 & 0,214 \\
\hline Rio G. Norte & 46,81 & 32,96 & 16,48 & 0,10 & 0,157 \\
\hline Sergipe & 55,13 & 5,32 & 2,16 & 0,05 & $-0,131$ \\
\hline Sudeste & 32,32 & 13,49 & 6,75 & 0,12 & 0,229 \\
\hline Espírito Santo & 23,29 & 54,92 & 34,03 & 0,19 & 0,476 \\
\hline Minas Gerais & 41,20 & 5,80 & 2,90 & 0,10 & 0,077 \\
\hline Rio de Janeiro & 39,45 & 25,81 & 10,50 & 0,04 & 0,181 \\
\hline São Paulo & 27,87 & 13,14 & 6,57 & 0,13 & 0,260 \\
\hline Sul & 41,69 & 9,18 & 3,55 & 0,14 & 0,091 \\
\hline Paraná & 40,16 & 9,31 & 3,74 & 0,15 & 0,120 \\
\hline Rio G. do Sul & 45,15 & 8,61 & 3,42 & 0,15 & 0,049 \\
\hline Santa Catarina & 45,98 & 8,98 & 2,88 & 0,11 & 0,056 \\
\hline Centro-Oeste & 47,31 & 9,39 & 4,70 & 0,19 & 0,054 \\
\hline Distrito Federal & 22,59 & 16,12 & 2,94 & 0,11 & 0,345 \\
\hline Goiás & 49,84 & 9,96 & 4,98 & 0,14 & 0,018 \\
\hline Mato Grosso & 43,04 & 11,39 & 5,70 & 0,20 & 0,092 \\
\hline Mato G. do Sul & 54,60 & 4,07 & 2,04 & 0,26 & $-0,041$ \\
\hline Brasil & 35,32 & 12,73 & 6,37 & 0,13 & 0,186 \\
\hline
\end{tabular}

Fonte: Elaboração própria, a partir de dados do Censo Agropecuário 2006.

produção, que chega a 24,4 e $42,3 \%$, respectivamente. Essa participação é também desproporcional no estado da Bahia, da ordem de 9,5 e 19,0\%, e em São Pulo, onde atinge 6,6 e 13,1\% , na mesma ordem. Já em Amazonas e Distrito Federal, os estabelecimentos responsáveis pelos últimos $5 \%$ da produção utilizam proporcionalmente menos financiamentos. Em todos esses estados a parcela dos financiamentos tomados pelos estabelecimentos correspondentes aos primeiros $50 \%$ do valor produzido situa-se na faixa de $20-30 \%$.
Nos estados de Mato Grosso, Minas Gerais, Santa Catarina, Rondônia, Rio Grande do Sul, Goiás, Paraíba, Mato Grosso do Sul, Tocantins, com índices de concentração inferiores a 0,10, em valor absoluto, observa-se que a distribuição dos financiamentos tende a ser proporcional à participação dos estratos no valor da produção. No estado de Sergipe, e principalmente Amapá, o uso de financiamentos é proporcionalmente maior entre os estabelecimentos correspondentes à primeira metade do valor produzido. 
Nos demais estados o índice de concentração situa-se na faixa de 0,10-0,20. Neles, de modo geral, há proporcionalmente maior uso de financiamento nos estratos superiores do valor da produção, e a participação dos estabelecimentos correspondentes à primeira metade do valor produzido nos financiamentos encontra-se na faixa de $35-40 \%$, com exceção de Rio Grande do Norte e Acre, onde ela é próxima de $45 \%$.

Os dados do Censo Agropecuário permitem distinguir os financiamentos provenientes de programas de crédito dos que não são provenientes de programas de crédito, aqui referidos como outras fontes. No ano de 2006, esses recursos corresponderam a 57,31 e $42,69 \%$, respectivamente, do total dos financiamentos tomados. Na Figura 2 , pode-se notar que os recursos não provenientes de programas de crédito concentram-se nos estratos superiores da distribuição. Os estabelecimentos com áreas de 200 ha ou mais respondem por cerca de $80 \%$ desses recursos, mas a apenas $50 \%$, aproximadamente, dos recursos provenientes de programas de crédito.

Nesse sentido, a relação mais equitativa entre uso de financiamentos e a contribuição dos estabelecimentos para o valor da produção está particularmente associada aos recursos provenientes de programas de crédito. Por sua vez, a melhor distribuição dos recursos provenientes de programas de crédito deve-se, em grande medida, à existência do Pronaf. Conforme Figura 3, cerca de 90\% dos recursos provenientes desse programa foram empregados por estabelecimentos de até 200 ha. Já os estabelecimentos com área superior a 200 ha responderam por cerca de $70 \%$ dos recursos de programas de crédito, exceto Pronaf.

Figura 2. Distribuição dos financiamentos (programas de crédito, outras fontes e total) entre os estabelecimentos, segundo estratos de área, 2006

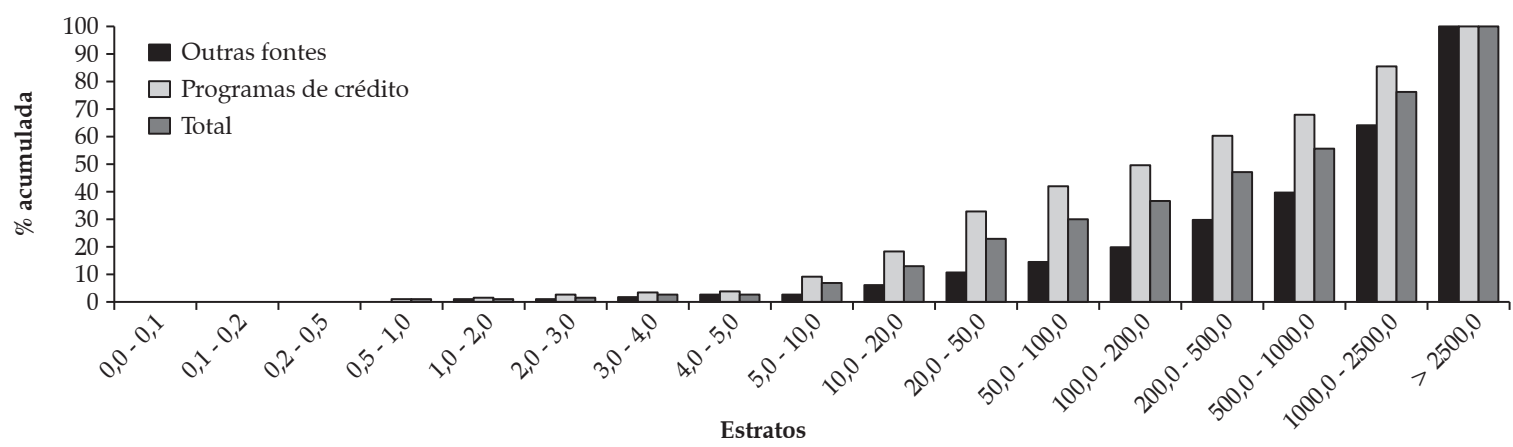

Fonte: Elaboração própria, a partir de dados do Censo Agropecuário 2006.

Figura 3. Distribuição dos financiamentos (Pronaf e Programas-Pronaf) entre os estabelecimentos segundo estratos de área, 2006

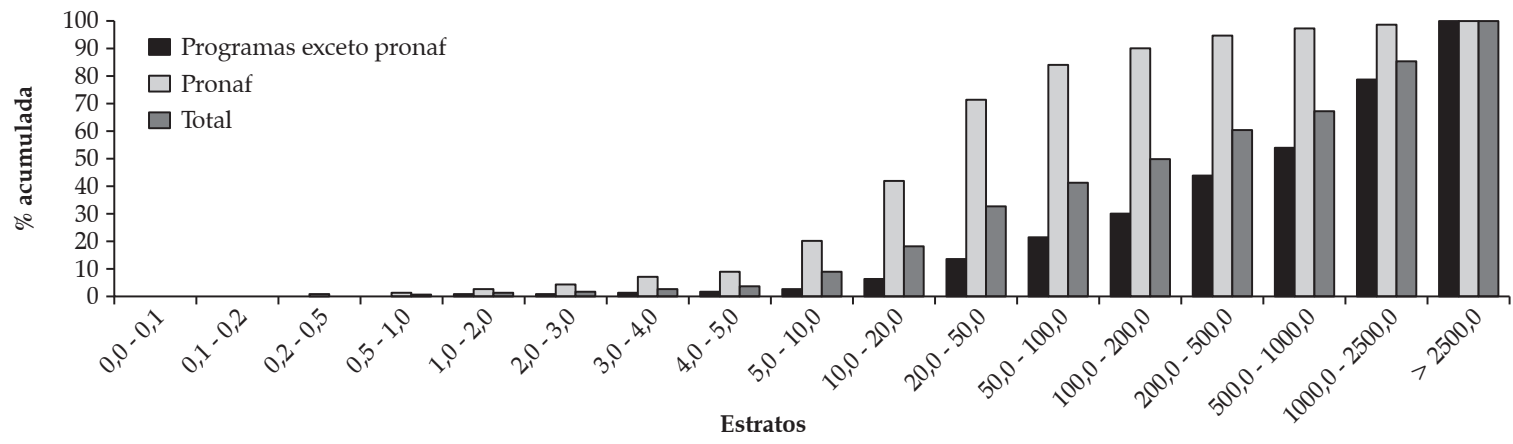

Fonte: Elaboração própria, a partir de dados do Censo Agropecuário 2006. 
Isso pode ser também observado nas Figuras 4a e 4b. As curvas de concentração exibidas na Figura 4a descrevem o comportamento da distribuição dos financiamentos entre os estabelecimentos, estes ordenados segundo estratos crescentes de área. Já as curvas da Figura 4b descrevem a relação entre a distribuição acumulada dos financiamentos e a distribuição acumulada do valor da produção, obtidas mediante ordenação crescente dos estratos de área.

Pode-se observar que, tanto pelo critério estabelecimentos como pelo critério valor da produção, o Pronaf, pela sua própria concepção, apresenta distribuição menos concentrada do que as demais fontes. Pelo critério valor da produção, a curva de concentração do Pronaf está inclusive acima da linha de igualdade e, portanto, favorece os estabelecimentos dos menores estratos de área, de baixa participação individual no valor produzido. Já a distribuição dos financiamentos oriundos de programas governamentais, excetuado o Pronaf (programas - Pronaf), é semelhante à distribuição dos financiamentos advindos de outras fontes e ambas tendem a se concentrar em estabelecimentos dos estratos superiores de área.

Ou seja, o advento do Pronaf contribuiu para reduzir a concentração no uso de financiamentos pela agropecuária, mediante redução na concentração da distribuição dos recursos públicos. Nas Figuras 5 a e 5 b pode-se constar que, na ausência do Pronaf, as curvas de concentração da distribuição dos financiamentos provenientes de programas, pelos estabelecimentos ou pelo valor da produção, seriam bem mais concentradas.

De todo o modo, embora o Pronaf contribua para melhorar a distribuição dos recursos públicos entre os estabelecimentos, a distribuição total do uso dos financiamentos permanece concentrada, devido aos recursos provenientes de outras fontes. Com mostram as Figuras 6a e $6 \mathrm{~b}$, o uso de financiamentos pela agropecuária brasileira é, ainda, proporcionalmente maior nos estratos superiores da distribuição da área e do valor da produção.

Figura 4. (a) Curvas de concentração da distribuição do valor dos financiamentos (Pronaf, programas-pronaf e outras fontes) entre estabelecimentos, 2006. (b) Curvas de concentração da distribuição dos financiamentos

(Pronaf, programas-pronaf e outras fontes) pelo valor da produção, 2006.

(a)

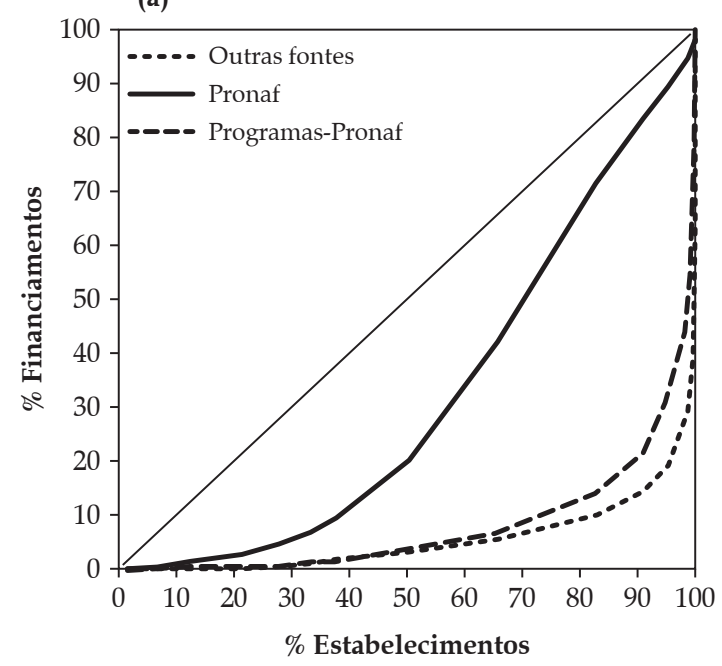

(b)

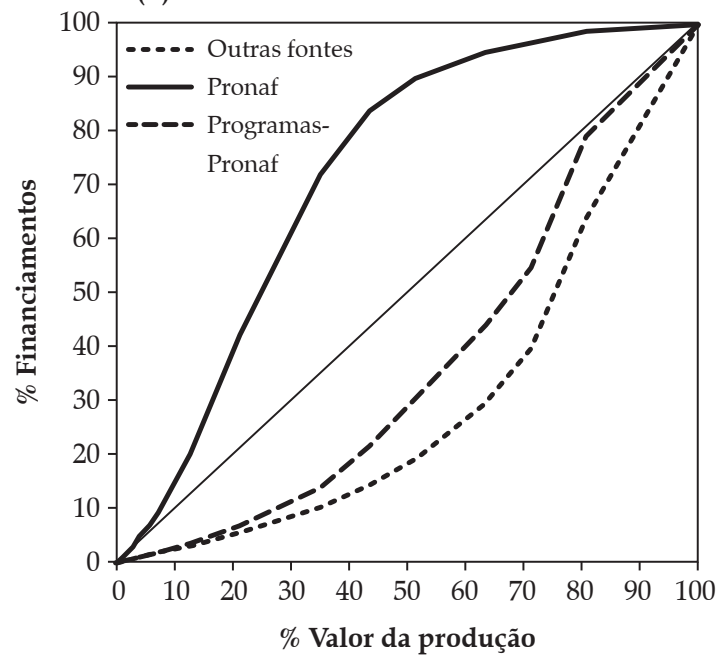

Fonte: Elaboração própria, a partir de dados do Censo Agropecuário 2006. 
Figura 5. (a) Curvas de concentração da distribuição do valor dos financiamentos (programas e programas-pronaf) entre estabelecimentos, 2006. (b) Curvas de concentração da distribuição dos financiamentos (Programas e programas-pronaf) pelo valor da produção, 2006.

(a)

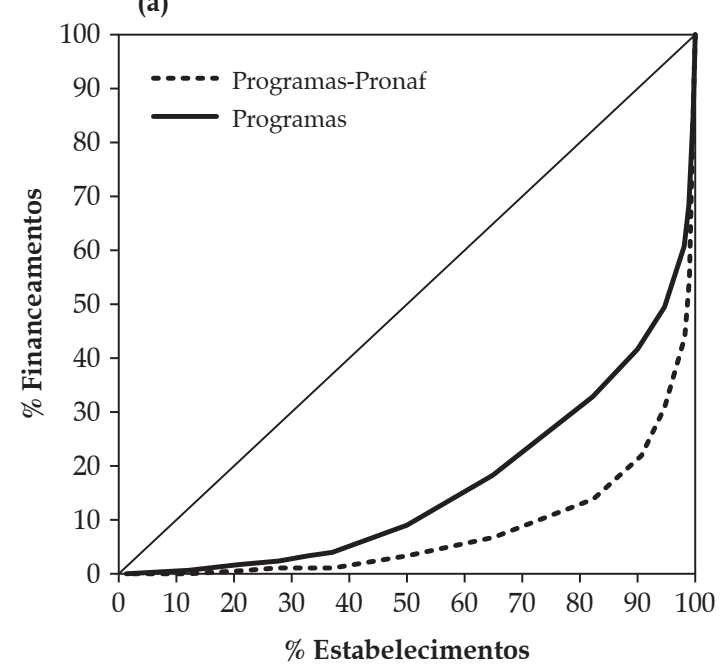

(b)

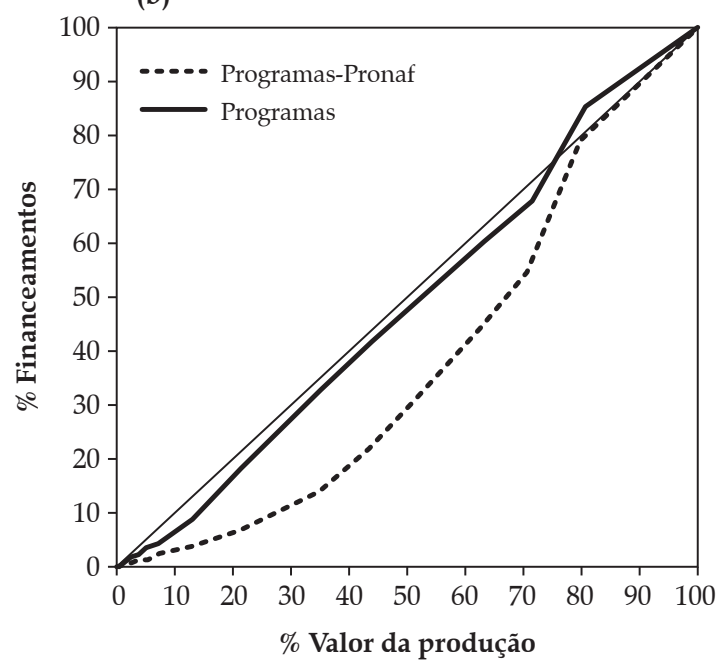

Fonte: Elaboração própria, a partir de dados do Censo Agropecuário 2006.

Figura 6. (a) Curvas de concentração da distribuição do valor dos financiamentos (total e total-pronaf) entre estabelecimentos, 2006; (b) Curvas de concentração da distribuição dos financiamentos (total e total-pronaf) pelo valor da produção, 2006.

(a)

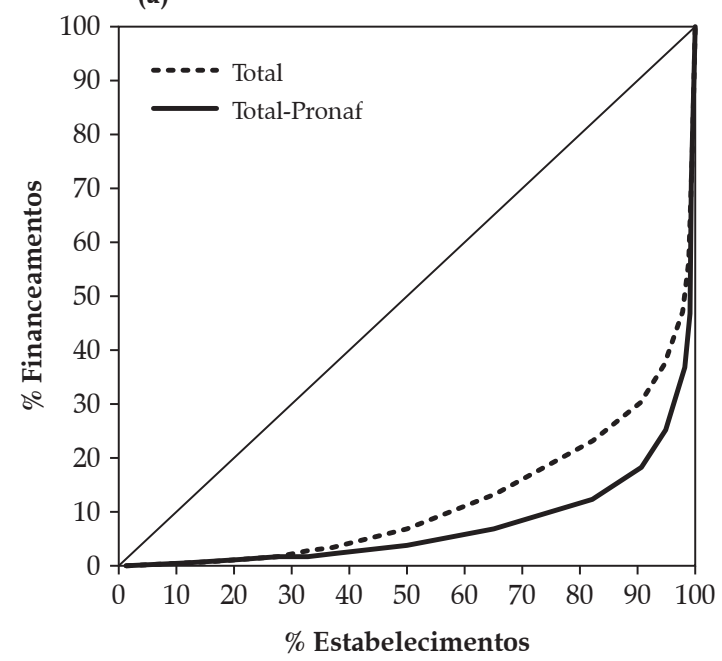

(b)

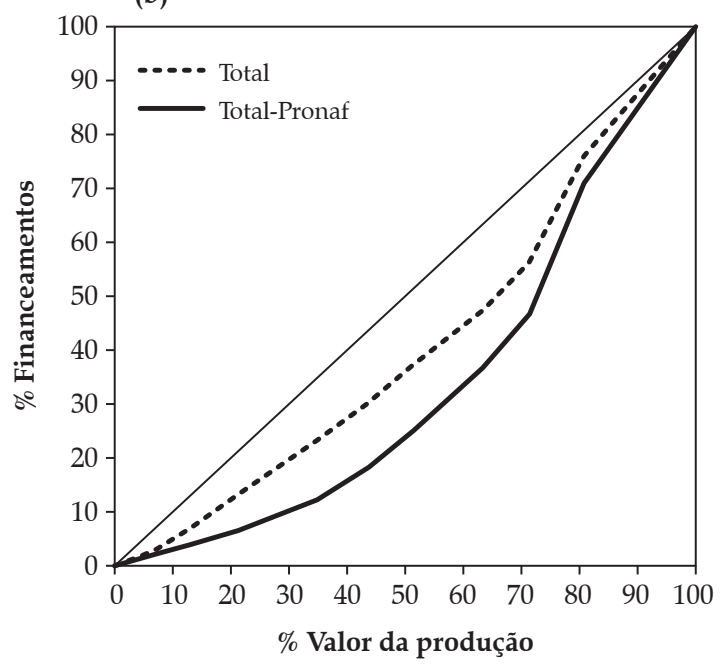

Fonte: Elaboração própria, a partir de dados do Censo Agropecuário 2006.

Algumas análises recentes, feitas com base nos dados do Censo, corroboram esses resultados. Dias (2010) destaca que o grupo de produtores que possuem 500 ha de terra ou mais têm alto acesso aos financiamentos. Nesse grupo, os finan- ciamentos obtidos superam em $22 \%$ os investimentos realizados. Segundo o autor, enquanto os menores estabelecimentos investem com suas próprias poupanças, os grandes contam com mais contribuição dos financiamentos com juros 
subsidiados. Por outro lado, Barros (2010) ressalta o baixo uso de financiamentos entre os pequenos produtores, dentre os quais apenas $18 \%$ conseguiram acessá-los em 2006. Também Alves, Souza e Rocha (2012) constataram que a pequena produção gastou muito menos por hectare, possivelmente refletindo discriminação pelo mercado ou a personalidade do agricultor. Não por acaso, dentre as principais recomendações dos autores para a política agrícola, que incluem investimentos na extensão rural, na infraestrutura de transportes, no controle de riscos climáticos e de preços, dentre outras, destaca-se a necessidade de eliminar as restrições de acesso ao crédito rural.

É preciso fazer a ressalva de que o baixo uso de financiamentos por pequenos estabelecimentos não pode ser diretamente associado à restrição ou viés seletivo. Isso porque a percepção da necessidade de financiamento, que precede a busca por esse recurso, é afetada por uma série de fatores, como nível educacional, acesso à assistência técnica, grau de organização, etc., em geral baixos entre os pequenos estabelecimentos.

Segundo Souza (2011), cerca de metade dos estabelecimentos familiares que informaram não ter utilizado financiamento em 2006 alegou não ter precisado. O medo da dívida, a burocracia e a existência de débito anterior representaram, juntos, a justificativa de $33,5 \%$ dos estabelecimentos. Esses motivos foram maiores na região Nordeste, onde o medo da dívida foi, isoladamente, apontado em quase $27 \%$ dos estabelecimentos como motivo para não utilizar financiamento.

De qualquer modo, é alto o percentual dos agricultores familiares que afirmaram não precisar de crédito. Uma das razões possíveis é o baixo padrão tecnológico de boa parte dos menores estabelecimentos, onde predominam tecnologias tradicionais, pouco intensivas em insumos externos e recursos financeiros, que reduz a percepção da necessidade de financiamentos. Isso pode ser entendido a partir das informações de Guanzirolli (2007), que dão conta dos baixos índices de adoção de tecnologias pela agricultura familiar, que ocorrem principalmente nas regiões Norte e Nordeste. O uso de assistência téc- nica por esses agricultores, elemento importante para o acesso aos financiamentos (EUSÉBIO e PENHA, 2014), também é muito baixo, sobretudo na região Nordeste.

Deve-se também considerar a importância do emprego não-agrícola na ocupação da força de trabalho do meio rural. De um lado, parte da renda monetária obtida por membros da família em atividades não agrícolas pode ser aplicada no estabelecimento, custeando a produção e reduzindo as necessidades de financiamento. Por outro, essas ocupações também vêm limitando o enquadramento de famílias pluriativas, eliminadas pelo critério de procedência da renda obtida (LIMA et al., 2013).

De todo o modo, os resultados permitem inferir que persiste a desigualdade na distribuição dos financiamentos governamentais, situação amenizada com o surgimento do Pronaf. Além das questões relacionadas ao mercado de crédito e à seletividade imposta pelas instituições financeiras, a existência de mecanismos de resistência à mudança institucional, ou, conforme a literatura de economia institucional, a presença de path dependence (NORTH, 1990), pode explicar em parte essas desigualdades. Esse conceito atribui importância à trajetória ou herança histórica das instituições, concebidas, num sentido mais amplo, como as normas, crenças, condutas e regras que regem as interações sociais, limitam e definem as escolhas possíveis das organizações. A evolução dessas instituições tende a seguir trajetórias forjadas no passado e a compreensão das escolhas atuais passa pelo entendimento da evolução precedente dessas instituições (NORTH, 1990).

Essa subordinação das instituições à trajetória pode resultar em efeitos duradouros sobre o desenvolvimento econômico, já que os modelos institucionais tendem a se auto-reforçarem, mesmo quando não são os mais eficientes. Ineficientes para a sociedade, mas interessantes para determinados grupos e organizações, que pugnam pela sua manutenção.

Essa percepção é, em parte, sustentada em algumas análises. Conforme Delgado (2012), as estratégias adotadas no período da "moderniza- 
ção conservadora" possibilitaram um processo de acumulação de capital nos setores agrícolas e agroindustriais, fortemente amparado pelo dinheiro público, particularmente com a criação do Sistema Nacional de Crédito Rural. A partir de meados dos anos 80, o fim do regime militar, sucedido por período de transição que reorganiza o Estado e suas atribuições, dá vez às novas demandas sociais. Esse contexto desorganiza parcialmente o projeto da modernização conservadora, e enseja o início da transição para uma nova aliança do poder agrário com o Estado.

Nessa nova fase, alianças de grupos econômicos para capturar o excedente econômico, políticas agrícolas generosas e projeto de hegemonia ideológica são elementos que se aglutinam. Essa aliança, segundo o autor, reafirma a estrutura anterior, um sistema de relações de produção das cadeias agroindustriais com a agricultura, alavancado pelo sistema de crédito público e pela renda fundiária (DELGADO, 2012). Segundo Silva (2010), tendo caído o ideal unitário de representação de interesses que predominara anteriormente, o protecionismo estatal, antes de assistencial-defensivo, adquire agora um caráter permanente, pois passa a ser considerado condição essencial para a integração dos produtores rurais aos oligopólios que dominam a economia moderna.

Nesse sentido, interesses contrários às mudanças institucionais na política de crédito têm prevalecido. Para além da questão distributiva aqui tratada, destacam-se os conflitos decorrentes de crises de endividamento rural que, como destacado por Dias (2006), termina canalizado para o governo. Nessa instância, a representação política dos grupos de interesse cria um viés pela socialização dos custos e concentração dos benefícios. No que tange ao crédito rural, as evidências, segundo Silva (2010), são de que os devedores persistem na inadimplência, mesmo nos anos de boas safras e preços altos, habituados a renegociarem suas dívidas em melhores condições.

Quanto ao papel do Pronaf, é preciso ressaltar que as informações utilizadas na análise referem-se a 2006, ano caracterizado por uma melhor distribuição de seus recursos. Essa distribuição, na fase inicial do programa, caracterizava-se pela forte concentração dos financiamentos nos estados da região Sul (GUANZIROLI, 2007; MATTEI, 2005) e nos segmentos mais capitalizados da agricultura familiar (FIGUEIREDO, SILVA e SANTOS, 2006; SILVA, CORREA e NEDER, 2007). Posteriormente, foram sendo implementadas mudanças institucionais e financeiras que possibilitaram melhorar a distribuição dos recursos entre regiões e entre níveis de renda dos agricultores familiares (SCHNEIDER, CAZELLA e MATTEI, 2004). Essa melhora, que perdurou até o ano de 2006 (SOUZA, NEY e PONCIANO, 2011), contribuiu para elevar a participação da região Nordeste nos financiamentos do Pronaf, como pode ser observado na Figura 7.

Figura 7. Participação regional no valor do Pronaf-crédito, nos anos de 1999, 2006 e 2012

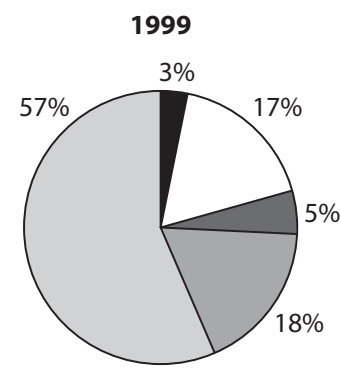

2006

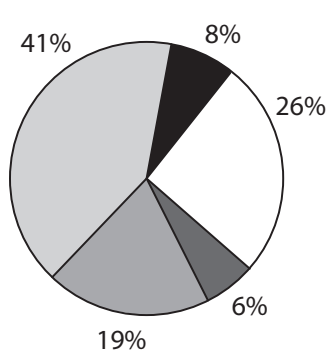

$19 \%$
2012

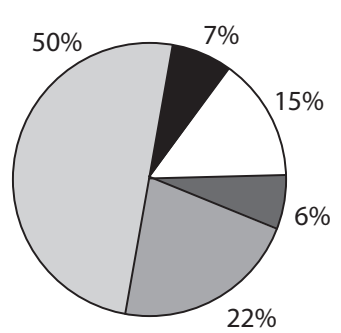

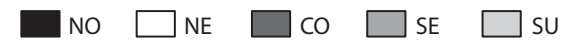

Fonte: Elaboração própria, a partir de dados do Banco Central do Brasil (2013). 
Tabela 3. Índices de concentração da distribuição dos financiamentos tomados, segundo o critério valor da produção, conforme a origem

\begin{tabular}{lcccc}
\hline \multicolumn{1}{c}{ Região } & Programas - Pronaf & Pronaf & Outras fontes & Total \\
\hline Norte & 0,25 & $-0,22$ & 0,44 & 0,14 \\
Nordeste & 0,52 & $-0,34$ & 0,50 & 0,29 \\
Sudeste & 0,32 & $-0,46$ & 0,31 & 0,23 \\
Sul & 0,27 & $-0,33$ & 0,31 & 0,09 \\
Centro-Oeste & $-0,10$ & $-0,56$ & 0,16 & 0,05 \\
Brasil & 0,24 & $-0,47$ & 0,39 & 0,19 \\
\hline
\end{tabular}

Fonte: Elaboração própria, a partir de dados do Censo Agropecuário de 2006

Porém, nos anos seguintes a desigualdade na distribuição dos financiamentos do Pronaf voltou a se elevar, provavelmente em decorrência de mudanças ocorridas nas normas do programa, favoráveis à crescente participação nos financiamentos dos agricultores mais capitalizados, bem como das regiões onde estes se concentram. Uma delas é o aumento do limite de renda bruta para fins de enquadramento no programa, acentuado na safra 2007/2008, que tem permitido o ingresso de agricultores com maior renda (AQUINO, 2009; AQUINO e SCHNEIDER, 2010). Além disso, o período foi marcado por mudanças nas fontes que financiam o Pronaf, com possíveis efeitos sobre a distribuição dos financiamentos. Em substituição aos recursos oriundos do Fundo de Amparo ao Trabalhador e do Orçamento Geral da União, de onde provinha a maior parte da dotação do programa, os recursos obrigatórios dos bancos assumem importância crescente. Nesse novo cenário, os bancos, cujo papel no direcionamento dos recursos cresceu, podem optar pelo financiamento de contratos maiores, com menor custo operacional e a juros mais altos, para os agricultores familiares mais capitalizados (DELGADO, LEITE e WESZ JÚNIOR, 2011).

Neste novo contexto, a região Nordeste, responsável por mais de um quarto do valor produzido na agricultura familiar, e onde se encontra cerca de metade dos estabelecimentos e do pessoal ocupado neste segmento, passa, em 2012, a receber apenas $15 \%$ dos financiamentos do Pronaf.

Como agravante, é nessa região, onde as dificuldades para acesso ao crédito tem sido conside- radas maiores (SOUZA et al., 2011; ASSUNÇÃO e CHEIN, 2007), que o papel do Pronaf se torna mais relevante. Na Tabela 3, observa-se que a distribuição dos financiamentos oriundos de programas públicos, exceto Pronaf, mostra-se especialmente concentrada na região Nordeste. Quando se consideram os índices da distribuição dos financiamentos advindos de outras fontes, nota-se que ela é parecida com a distribuição dos recursos de programas públicos (exceto Pronaf), e ligeiramente mais concentrada. Mas é também na região Nordeste que esta última distribuição tem o índice de concentração mais elevado.

Ou seja, se o Pronaf tem tido um papel importante na redução da desigualdade no uso de financiamentos é, sobretudo, na região Nordeste que esse papel assume maior relevância. Porém, com o aumento na desigualdade da distribuição regional desses financiamentos após 2006, dados de um novo Censo Agropecuário provavelmente indicariam menor contribuição do Pronaf para a redução da desigualdade na concessão dos financiamentos governamentais ${ }^{7}$. Pelas razões cita-

7. É importante destacar que as informações do Banco Central resultam de registros das operações de crédito efetuadas nos respectivos anos. As do Censo Agropecuário, por sua vez, resultam de informações dadas pelos responsáveis pelos estabelecimentos quando da aplicação do instrumento de coleta dos dados censitários (questionário). Trata-se, no primeiro caso, do valor total dos contratos de crédito firmados; no segundo, do valor dos financiamentos obtidos pelos estabelecimentos, conforme informação de seus responsáveis. Por conta disso, diferenças na distribuição regional dos recursos podem ser encontradas entre as duas fontes. De todo o modo, e não se dispondo ainda de um novo Censo Agropecuário, admite-se aqui que a piora na distribuição regional dos financiamentos 
das, isso afetaria, sobretudo, a região Nordeste, onde os efeitos do Pronaf seriam drasticamente reduzidos.

\section{Conclusões}

Buscou-se, com a presente pesquisa, analisar a distribuição do uso de financiamentos entre os estabelecimentos, considerando tais critérios: número de estabelecimentos e participação no valor da produção. Os resultados permitiram concluir que a distribuição dos financiamentos entre os estabelecimentos agropecuários é concentrada. Enquanto os 50\% menores estabelecimentos empregam cerca de apenas $6,5 \%$ do total de financiamentos, os $5 \%$ maiores utilizam quase $63 \%$, e os $10 \%$ maiores $70 \%$ desse total. Segundo esse critério, a distribuição dos financiamentos mostra-se mais concentrada nas regiões CentroOeste e Sudeste, e mais equitativa nas regiões Norte e Sul.

Essa concentração reflete, em parte, as diferenças entre estabelecimentos quanto ao tamanho da área e a sua contribuição para o valor da produção. Assim, quando comparada com a distribuição do valor da produção, a distribuição dos financiamentos mostrou-se mais equitativa, porém ainda concentrada. No país, constatou-se que os maiores estabelecimentos, responsáveis pelos últimos 5 e $10 \%$ do valor da produção, utilizam cerca de 6,4 e 12,7\% dos financiamentos. Os menores, responsáveis pelos primeiros $50 \%$ do valor da produção, utilizam apenas 35,3\% dos financiamentos. Constatou-se ainda que essa disparidade é maior nas regiões Nordeste e Sudeste, e menor nas regiões Sul e Centro-Oeste.

Por qualquer dos critérios empregados, mostrou-se a importância do Pronaf na redução da desigualdade no uso dos financiamentos. Trata-se de uma contribuição importante, uma

do Pronaf no período posterior a 2006, identificada a partir dos dados do Banco Central, contribuirá para elevar a desigualdade da distribuição dos financiamentos obtidos pelos estabelecimentos. vez que, confirmando inúmeras críticas do passado, os financiamentos oriundos da política de crédito rural continuam a se concentrar nos estratos superiores de área e de valor da produção.

Na ausência do Pronaf, cujas normas impõem barreiras à entrada de agricultores pertencentes a esses estratos, a distribuição dos financiamentos oriundos de programas governamentais seria mais concentrada. Porém, as mudanças nas regras de operacionalização desse programa, que vêm permitindo crescente apropriação de seus recursos por agricultores mais capitalizados e pelas regiões onde eles predominam, provavelmente vêm anulando os impactos positivos do Pronaf para a redução da desigualdade no acesso aos financiamentos.

Em síntese, os resultados evidenciam uso proporcionalmente menor de financiamentos pelos estabelecimentos de menor tamanho. De início, há que se considerar que nem todos os estabelecimentos que deixam de tomar crédito o fazem por encontrar obstáculos e restrições nas instituições que o operam. Nesse sentido, há evidências de que muitos agricultores não usam financiamento por entenderem não precisar desse recurso. Questões como nível de instrução, acesso à assistência técnica, padrão tecnológico predominante, acesso a fontes externas aos estabelecimentos, dentre outros fatores, podem estar na base dessa percepção.

De todo o modo, constatou-se que a desigualdade na distribuição dos financiamentos governamentais, criticada na fase da chamada modernização conservadora, ainda persiste. Tal persistência, por hipótese, pode estar associada às características do mercado de crédito, cujas especificidades elevam os custos das operações, restringem a oferta e impõem um viés seletivo contrário aos pequenos tomadores. Por outro lado, essa persistência pode estar associada à hipótese de path dependence, segundo a qual a evolução das instituições dependem de trajetórias traçadas no passado. Nesse sentido, análises têm revelado a ação de grupos de interesse contrários às mudanças institucionais na política de crédito, que historicamente os tem favorecido. 


\section{Referências}

ALVES, E., SOUZA, G. S. e ROCHA, D. P. Lucratividade da agricultura. Revista de Política Agrícola, n. 2, p. 45-63, abr.jun. 2012.

AQUINO, J. R. Avanços e limites da política de crédito do PRONAF no Brasil (1996-2008): uma reflexão crítica. In: Congresso da Sociedade Brasileira de Economia, Administração e Sociologia Rural, 47., 2009, Porto Alegre. Anais... Brasília: SOBER, 2009.

.; SCHNEIDER, S. 12 anos da política de crédito do PRONAF no Brasil (1996-2008): uma reflexão crítica. Congresso Latino Americano de Sociologia Rural, 8, Porto de Galinhas, 2010. p. 1- 8. Anais... ALASRU, 2010.

ASSUNÇÃO, J. e CHEIN, F. Condições de crédito no Brasil rural. Revista de economia e sociologia Rural, Rio de Janeiro, v. 45, n. 02, p. 367-407, abr.jun. 2007.

BANCO CENTRAL DO BRASIL. Anuário Estatístico do Crédito Rural. Disponível em: <www.bcb.gov.br>. Acesso em: nov. 2013.

BARROS, G. S. C. Política agrícola no Brasil: subsídios e investimentos. In: GASQUES, J. G., VIEIRA FILHO, J. E. R. e NAVARRO, Z. (Org.). A agricultura brasileira: desempenho, desafios e perspectivas. Brasília: IPEA, 2010. p. 237-258.

BELIK, W. O financiamento da agropecuária brasileira e seu desempenho no período recente. In: Congresso da Sociedade Brasileira de Economia, Administração e Sociologia Rural, 51., 2013, Belém. Anais... Brasília: SOBER, 2013.

O Financiamento da Agricultura Familiar no Brasil na década de 2000. In: Congresso da Sociedade Brasileira de Economia, Administração e Sociologia Rural, 52., 2014, Goiânia. Anais... Brasília: SOBER, 2014.

DELGADO, G. C. Do capital financeiro na agricultura à economia do agronegócio: mudanças cíclicas em meio século (1965-2012). Porto Alegre: UFRGS, 2012. 144p.

DELGADO, N., LEITE, S. P. e WESZ JÚNIOR, V. Nota técnica sobre financiamento rural no Brasil. Rio de Janeiro: UFRJ/CPDA, out. 2011. (Observatório de Políticas Públicas para a agricultura). 11p.

DIAS, G. L. S. O Estado e o agro em tempos de liberalização. Revista Economia e Sociologia Rural, v. 44, n. 3, p. 341-354, jul./set. 2006.

A dificuldade de mudar: o caso da política agrícola no Brasil. In: GASQUES, J. G., VIEIRA FILHO, J. E. R. e NAVARRO, Z (Org.). A agricultura brasileira: desempenho, desafios e perspectivas. Brasília: IPEA, 2010. p. 259-274.

EUSÉBIO, G. S.; PENHA, T. A. M. Uma análise do acesso ao crédito rural para o Estado de São Paulo. In: Congresso da Sociedade Brasileira de Economia, Administração e Sociologia Rural, 52., 2014, Goiânia. Anais... Brasília: SOBER, 2014.

FIGUEIREDO, A. M., SILVA, M. A. P. e SANTOS, M. L. Distribuição Estadual dos Recursos do PRONAF e sua Comparação com a Renda dos Produtores Familiares. Congresso Brasileiro de Economia e Sociologia Rural, 44., 2006, Fortaleza. Anais... Brasília: SOBER, 2006.

GUANZIROLI, C. E. PRONAF dez anos depois: resultados e perspectivas para o desenvolvimento rural. Revista de Economia e Sociologia Rural, Rio de Janeiro, v. 45, n. 2, p. 301-328, abr.jun. 2007.

HELFAND, S. M., MOREIRA, A. R. B. e BRESNYAN JUNIOR, E. W. Agricultura familiar, produtividade e pobreza no Brasil: evidências do censo agropecuário 2006. In: SCHNEIDER, S., FERREIRA, B. e ALVES, F. (Org.). Aspectos multidimensionais da agricultura brasileira: diferentes visões do Censo Agropecuário 2006. Brasília: Ipea, 2014. p. 279-311.

INSTITUTO BRASILEIRO DE GEOGRAFIA E ESTATÍSITCA. Sistema de recuperação automática de dados-SIDRA. Censo Agropecuário 2006 (segunda apuração). Disponível em: <http://www.sidra.ibge.gov. $\mathrm{br} / \mathrm{bda} /$ pesquisas $/ \mathrm{ca} /$ default.asp? $\mathrm{z}=\mathrm{p} \& \mathrm{o}=2 \& \mathrm{i}=\mathrm{P}>$. Acesso em: jan. 2014.

KAKWANI, N. Applications of Lorenz curves in economic analysis. Econometrica, v. 45, n. 3, p. 719-728, abr. 1977.

LIMA, F. A. X. et al. Políticas públicas e agricultura familiar: caracterização do acesso ao crédito em Santa Cruz da Baixa Verde-PE. In: Congresso da Sociedade Brasileira de Economia, Administração e Sociologia Rural, 51., 2013, Belém. Anais... Brasília: SOBER, 2013.

MATTEI, L. Impactos do PRONAF: análise de indicadores. Brasília: Ministério do Desenvolvimento Agrário, núcleo de estudos agrários e Desenvolvimento Rural. Série Estudos NEAD: 11, 136 p. 2005.

MEDEIROS, M. Uma introdução às representações gráficas da desigualdade de renda. Brasília: IPEA, 2006. 43p. (TEXTO PARA DISCUSSÃO No 1202).

NORONHA, K.V.M.S.eANDRADE,M.V.Desigualdades sociais em saúde: evidências empíricas sobre o caso brasileiro. Belo Horizonte: UFMG/Cedeplar, 2002. 34p. (Texto para discussão; 171) 
NORTH, D. C. Institutions, institutional change and economic performance. New York: Cambridge University Press, 1990. 159p.

SAYAD, J. Crédito rural no Brasil: avaliação das críticas e das propostas de reforma. São Paulo: FIPE/Pioneira, 1984. 125p.

OLIVEIRA, L. M. et al. Fatores que influenciam a tomada de crédito do PRONAF nos municípios de Irituia e Santa Maria do Pará. In: Congresso da Sociedade Brasileira de Economia, Administração e Sociologia Rural, 51., 2013, Belém. Anais... Brasília: SOBER, 2013.

SANTOS, R. B. N. e BRAGA, M. J. Impactos do crédito rural na produtividade da terra e do trabalho nas regiões brasileiras. Economia Aplicada, v. 17, n. 3, 2013, p. 299-324.

SCHNEIDER, S., CAZELLA, A. e MATTEI, L. F. Histórico, caracterização e dinâmica recente do PRONAF - Programa Nacional de Fortalecimento da Agricultura Familiar. In: SCHNEIDER, S., SILVA, M. K. e MARQUES, P. E. M. (Org.). Políticas Públicas e Participação Social no Brasil Rural. Porto Alegre: Editora da UFRGS, 2004, p. 21-50.

SILVA, F. F., CORREA, V. P. e NEDER, H. D. Estudo comparativo da distribuição de recursos do PRONAF Crédito e Infra-estrutura, nas regiões Sul e Nordeste do Brasil: uma abordagem estatística. In: ORTEGA, A. C. e ALMEIDA FILHO, N. (Org.). Desenvolvimento Territorial, Segurança Alimentar e Economia Solidária. Campinas: Alínea, 2007, v. 1, p. 123-158.

SILVA, J. G. Os desafios das agriculturas brasileiras. In: GASQUES, J. G., VIEIRA FILHO, J. E. R. e NAVARRO, Z. (Org.). A agricultura brasileira: desempenho, desafios e perspectivas. Brasília: IPEA, 2010. p. 157-183.

. et al. Tecnologia e campesinato: o caso brasileiro. $\overline{R e v i s t a}$ de Economia Política, v. 3, n. 4, p. 21-55, out./dez. 1983.

SIMÕES, A. P.; PAQUETE, A. T.; ARAÚJO, M. Equidade horizontal no acesso a consultas de clínica geral, cardiologia e medicina dentária em Portugal. Revista Portuguesa de Saúde Pública, v. 26, n. 1, p. 39-52, jan.jjun. 2008.
SOUZA, P. M. et al. Agricultura familiar versus agricultura não-familiar: uma análise das diferenças nos financiamentos concedidos no período de 1999 a 2009. Revista Econômica do Nordeste, v. 42, n. 1., jan./mar. 2011. p. 105-124.

., NEY, M. G. e PONCIANO, N. J. Evolução da distribuição dos financiamentos do PRONAF entre as Unidades da Federação, no período de 1999 a 2009. Revista Brasileira de Economia, v. 65, p. 303-313, 2011.

SPOLADOR, H. F. S. e LIMA, R. A. S. Estimativa de concentração e distribuição regional de crédito agrícola no Brasil, no período 2000 a 2008. In: Congresso da Sociedade Brasileira de Economia, Administração e Sociologia Rural, 48, 2010, Campos Grande. Anais... Brasília: SOBER, 2010.

SPOLADOR, H. F. S. Reflexões sobre a experiência brasileira de financiamento agrícola. 2001. 102 f. Dissertação (Mestrado) - Curso de Economia Aplicada, Escola Superior de Agricultura Luiz de Queiróz, Piracicaba, 2002.

SZMRECSÁNYI, T. e RAMOS, P. O papel das políticas governamentais na modernização da agricultura brasileira. In: SZMRECSÁNYI, T. e SUZIGAN, W. (Org.). História Econômica do Brasil Contemporâneo. 2. ed. São Paulo: HUCITEC/Associação Brasileira dos Pesquisadores em História Econômica /Editora da Universidade de São Paulo, 2002. p. 227-250.

VIANA, J. S., SALVATO, M. A. e ARAÚJO, J. R. Tem sido a oferta pública de educação um fator relevante para a redução da desigualdade de renda? O caso da região sul brasileira, 2003 e 2009. In: Encontro de Economia da Região Sul, 12, 2011, Florianópolis. Anais... Florianópolis, 2011.

., SALVATO, M. A. e FRANÇA, N. C. A desigualdade educacional é importante para explicar a desigualdade de renda? uma análise para Brasil, regiões e unidades da federação entre 2003 e 2009. In: Encontro Nacional de Economia/ANPEC, 39, Foz do Iguaçu, 2011. Anais... Foz do Iguaçu, ANPEC, 2011. 
